\title{
Study of Gas Diffusion Multivariate Regression Model
}

\author{
Ying Zhou \\ Inner Mongolia University of Technology \\ College of Information Engineering \\ Hohhot 010080, China \\ E-mail: 1274018785@qq.com
}

\author{
Jian-Dong Fang \\ Inner Mongolia University of Technology \\ College of Information Engineering \\ Hohhot 010011, China \\ E-mail: fangjd@163.com
}

\begin{abstract}
With the rapid economic development, social demand for chemical products is increasing and the attendant problems have also emerged which the chemical gas will spill during transport. Therefore, understand the leaking gas diffusion trend has great effect on emergency rescue. Around the diffusion problem to tank leak source that may occur during road transportation, under the conditions, a diffusion model of gas leakage are established based on fluent simulation data. It means, establish a multiple regression model reference to regression analysis. The diffusion model was analyzed under the conditions of simulation data in MATLAB. The results show that the Multi-Regression Model can predict the spread of the gas leak in a certain extent. And the paper's research provides a theoretical basis for a gas leakage accident emergency rescue.
\end{abstract}

\section{Keywords-gas leakage; regression analysis; multiple regressions}

\section{INTRODUCTION}

Happened in recent years, successively more dangerous chemical transportation vehicle traffic accident caused the wide attention of the society. So after these accidents, how to scientific guidelines to the disposal of the accident rescue workers become more and more important. Gas diffusion behavior research is the basic theory of instruction for emergency rescue. Expert of our country's scholars in the field of leakage gas diffusion simulation research has achieved some results. In 2002, Jianke Du ${ }^{[1]}$ through the leakage gas diffusion model build the harm of gas regions division and estimation, And it could provide scientific and effective guidance at gas leakage accident rescue. In 2004, Ping $\mathrm{Li}^{[2]}$ analyzed the dangerous substances in tunnel before and after the release of the flow field during the vehicle movement, to study the dangerous chemical gas concentration distribution in vertical and horizontal directions. Dong Yan ${ }^{[3]}$ and others combined Gauss formula and three-dimensional finite element method to construct the leakage diffusion model of hazardous substances, and the model can be the rend of diffusion of dangerous substances and concentration distribution for effective estimation and evaluation. To sum up, although for the leakage of gas diffusion model, research has made certain achievements. But how to make the established model, constraint conditions, which has more extensively applicable scope is less, or create a new model to simulate the spread of leakage gas concentration, is still the problems we need to continue to study.

The establishment of the multiple regression models is based on fluent simulation data. First establishing single factor and diffusion concentration of monadic regression model. According to univariate regression model provide function relation, using the least squares algorithm, establish the direction of the wind speed and different diffusion distance and diffusion concentration between the multiple regression model and utilized fluid dynamics model calculation results as the reference standard, the inspection of the validity of the model. By the established leakage gas diffusion model, expect it could provide for road transport gas leakage accident emergency rescue.

\section{ALGORITHM RINCIPLE}

After the gas leak, it will be spread near the source under the influence of various factors. Gas diffusion process is not only influenced by its own nature, and also by the influence of factors such as wind speed and atmospheric stability. Apply EXCEL to establish wind speed and the diffusion rate, the concentration of the diffusion distance and the diffusion of univariate regression model.

\section{A. Establishment Of Univariate Regression Model}

In establishing univariate regression model and multiple regression model, that assume a homogeneous fluid flow the gas does not react in the diffusion process and the environment temperature is $300 \mathrm{k}$, turbulence intensity of 10 , leakage rate constant was $2.5 \mathrm{~m} / \mathrm{s}$, had no effect on the surface roughness of gas diffusion.

1) Under different wind speed conditions, the leakage of univariate regression analysis, the diffusion of the gas concentration by wind speed and the diffusion concentration of fitting formula is as follows:

$$
y=-0.0026 x^{4}+0.0134 x^{3}-0.0196 x^{2}-0.0005 x+1.1762
$$

In the formula:

$y$ _Leakage of gas concentration;

$x$ _ The leakage accident of wind speed

2) Under the different diffusion distance, he leakage of univariate regression analysis, the gas concentration and diffusion concentration diffusion distance fitting formula of the specific as follows:

$X$ axial distance and diffusion concentration of fitting formula is:

$$
y=2.2 E-6 x^{3}+5.3 E-6 x^{2}-4 E-5 x+1.1766
$$


In the formula:

$y-$ Leakage of gas concentration $\mathrm{kg} / \mathrm{m}^{3}$;

$X-X$ axial gas diffusion distance $/ m$

$Y$ axial distance and diffusion concentration of fitting formula is:

$$
y=-(4.3 E-6) x^{4}-0.00005 x^{3}+0.0002 x^{2}-0.000084 x+1.1766
$$

In the formula:

$$
\begin{aligned}
& y-\text { Leakage of gas concentration } \mathrm{kg} / \mathrm{m}^{3} \text {; } \\
& X-\text { Y axial gas diffusion distance } / \mathrm{m}
\end{aligned}
$$

\section{B. Establishment Of Multiple Regression Model}

On the basis of regression function in a univariate regression model using SPSS software to establish the wind speed, diffusion distance and the diffusion concentration of multivariate regression model, respectively the three input variables(wind speed ,X, Y diffusion distance) of primary, secondary and third power data and output variables (diffusion concentration) data entry in the form of column. Then return to operation, they will get the order variable regression coefficient of diffusion concentration, written formula as shown in the type:

$$
\begin{aligned}
y= & 1.17223+0.00016 x_{1}^{3}-0.00086 x_{1}^{2}-0.00259 x_{1}+0.00385 x_{2}^{3} \\
& -0.016395 x_{2}^{2}+0.01175 x_{2}+0.000493 x_{3}^{3}-0.0052 x_{3}^{2}+0.01344 x_{3}
\end{aligned}
$$

In the formula:

$x_{1}$ — the leakage accident of wind speed $\mathrm{m} / \mathrm{s}$;

$\mathrm{X}_{2}-\mathrm{X}$ axial gas diffusion distance/m;

$$
x_{3} \_ \text {Y axial gas diffusion distance/m }
$$

\section{SIMULATION AND RESULT ANALYSIS}

Due to the uncertainties in the diffusion process of the leaked gas, the model is established through different degrees of approximation and simplification. Therefore, in this paper, the most basic linear fitting algorithm is used to model the leakage data with three diffusion factors under certain conditions, and the fitting degree and prediction accuracy of the constructed diffusion model are tested by simulation experiments.

\section{A. Univariate Regression Model Simulation}

Leakage of gas diffusion concentration in different wind speed conditions are shown in table 1. By EXCEL the data in table 1 univariate regression analysis results (as shown in figure 1-1). Get wind speed and the diffusion concentration simulation result as follow:

TABLE I. TABLE GAS DIFFUSION CONCENTRATION UNDER DIFFERENT WIND CONDITIONS

\begin{tabular}{|c|c|c|c|}
\hline $\begin{array}{c}\text { wind } \\
\text { speed } \\
\mathbf{( m / s )}\end{array}$ & $\begin{array}{c}\text { gas diffusion } \\
\text { concentration } \\
\mathbf{( k g / \mathbf { m } ^ { 3 } )}\end{array}$ & $\begin{array}{c}\text { wind } \\
\text { speed } \\
\mathbf{( m / s )}\end{array}$ & $\begin{array}{c}\text { gas diffusion } \\
\text { concentration } \\
\mathbf{( k g / \mathbf { m } ^ { 3 } )}\end{array}$ \\
\hline 0.000000 & 1.176344 & 1.500002 & 1.163207 \\
\hline 0.100000 & 1.175502 & 2.000000 & 1.162125 \\
\hline 0.500010 & 1.173079 & 2.500000 & 1.158409 \\
\hline 1.000000 & 1.166243 & 3.000004 & 1.146456 \\
\hline
\end{tabular}

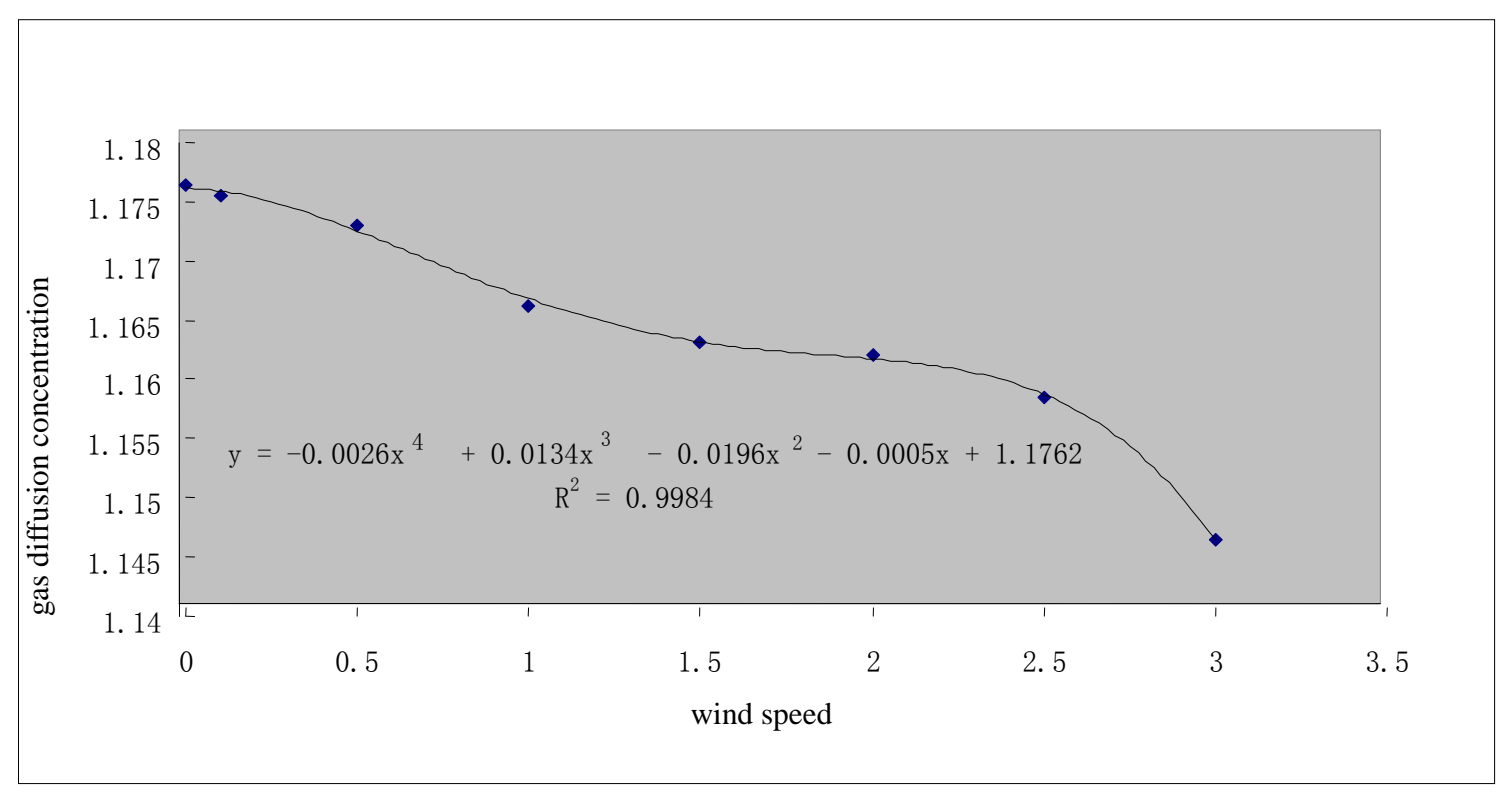

Figure 1-1. The relation chart of wind speed and the gas diffusion concentration.

From figure 1-1 wind speed and the concentration of gas diffusion fitting figure can be find that wind speed and concentration of four times univariate regression model can be better to response the relationship between wind speed 
and the diffusion concentration. Leakage of gas diffusion concentration under the conditions of different diffusion distance are shown in table 2 to 3 . In order to study its regularity, through analysis the application of EXCEL in table 2 and the data in table 3 univariate regression, the result can be obtained that diffusion distance and the diffusion concentration of specific simulation result is as follow:

TABLE II. TABLE X AXIAL DISTANCE AND THE GAS DIFFUSION CONCENTRATION

\begin{tabular}{cccc}
\hline \hline $\begin{array}{c}\text { X axial } \\
\text { distance } \\
\mathbf{( m )}\end{array}$ & $\begin{array}{c}\text { Diffusion } \\
\text { concentration } \\
\mathbf{( k g / \mathbf { m } ^ { 3 } )}\end{array}$ & $\begin{array}{c}\text { X axial } \\
\text { distance } \\
\mathbf{( m )}\end{array}$ & $\begin{array}{c}\text { Diffusion } \\
\text { concentration } \\
\mathbf{( k g / \mathbf { m } ^ { 3 } )}\end{array}$ \\
\hline 0.10000 & 1.17663 & 1.90000 & 1.176593 \\
0.30000 & 1.17662 & 2.00000 & 1.176594 \\
0.50000 & 1.17662 & 2.09999 & 1.176595 \\
0.80000 & 1.17661 & 2.20000 & 1.176596 \\
1.00000 & 1.17660 & 2.40000 & 1.176599 \\
1.10000 & 1.17659 & 2.50000 & 1.176602 \\
1.40000 & 1.17659 & 2.80000 & 1.176609 \\
1.50000 & 1.17659 & 3.00000 & 1.176627 \\
\hline \hline
\end{tabular}

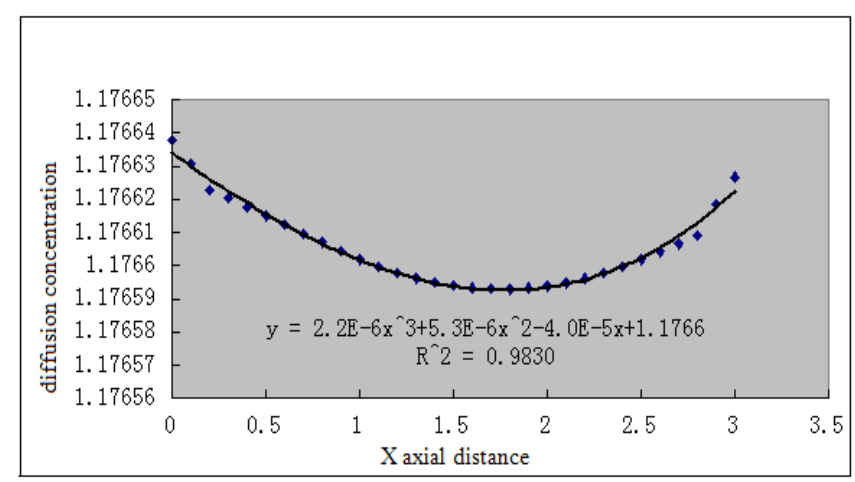

Figure 1-2. The relation diagram of $\mathrm{X}$ axial distance and the gas diffusion concentration.

TABLE III.TABLE Y AXIAL DISTANCE AND THE GAS DIFFUSION CONCENTRATION

\begin{tabular}{|c|c|c|}
\hline $\begin{array}{l}\text { Y axial distance } \\
(\mathrm{m})\end{array}$ & $\begin{array}{l}\text { Diffusion concentration } \\
\qquad\left(\mathrm{kg} / \mathrm{m}^{3}\right)\end{array}$ & $\begin{array}{c}\text { Y axial distance } \\
\text { (m) }\end{array}$ \\
\hline 0.10000 & 1.176638 & 2.90001 \\
\hline 0.50000 & 1.176619 & 3.00000 \\
\hline 0.80000 & 1.176602 & 3.20001 \\
\hline 1.00000 & 1.176589 & 3.40001 \\
\hline 1.30000 & 1.176567 & 3.90001 \\
\hline
\end{tabular}

From figure 1-2 and figure 1-3 can be seen, $\mathrm{X}$ axis diffusion distance and the diffusion concentration of three times univariate regression model fitting degree is $0.98 ; \mathrm{Y}$ axis diffusion distance and the diffusion concentration of four times univariate regression model fitting degree is 0.98 ; The two unary regression model to the original data of the fitting effect is considerable. The figure 1-3 shows as following:

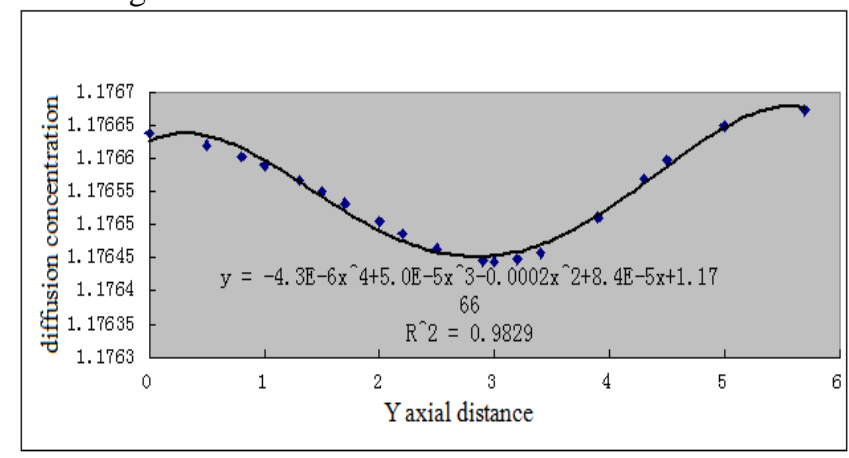

Figure 1-3. The relation diagram of $\mathrm{Y}$ axial distance and the gas diffusion concentration.

\section{B. Multiple Regression Model Simulation}

On the basis of a univariate regression function relationship, Use SPSS software to establish wind speed, diffusion distance and the diffusion concentration of multivariate regression model to inspect the accuracy of the inspection and test data model. Fitting test, it is for inspection has built prediction model of the most commonly used method, and it is always apply to the measure the model of the predicted results and the actual value, the fit of the commonly used computation formula is as follows:

$$
R^{2}=1-\frac{\sum(Y-\hat{Y})^{2}}{\sum(Y-\bar{Y})^{2}}
$$

In the formula, Y represent the actual value of diffusion concentration, represent the prediction of diffusion concentration, represent the average value of diffusion concentration. Through the calculation of type 5, the fit of the model of the value is .So it could be think that can better reflect the characteristics data, the test data and calculated results are shown in table 4.All test data of fluid dynamics model calculation results and the result compared with the predictive value of multivariate regression model is shown in figure 1-4. 
TABLE IV.

\begin{tabular}{|c|c|c|c|c|c|}
\hline $\begin{array}{c}\text { wind } \\
\text { spee } \\
\text { d } \\
(\mathrm{m} / \mathrm{s})\end{array}$ & $\begin{array}{c}\mathrm{X} \\
\text { axial } \\
\text { distan } \\
\text { ce (m) }\end{array}$ & $\begin{array}{c}X \\
\text { axial } \\
\text { distan } \\
\mathbf{c e} \\
(\mathbf{m} / \mathbf{s})\end{array}$ & $\begin{array}{c}\text { actual } \\
\text { concentration }((\mathbf{k g} / \\
\left.\left.\mathbf{m}^{3}\right)\right)\end{array}$ & $\begin{array}{c}\text { predict } \\
\text { concentrati } \\
\text { on }\left(\mathbf{k g} / \mathbf{m}^{3}\right)\end{array}$ & $\left.\begin{array}{l}\text { error } \\
(\mathrm{kg} / \mathrm{m} \\
3\end{array}\right)$ \\
\hline $\begin{array}{c}0.000 \\
0\end{array}$ & $\begin{array}{c}3.0000 \\
0\end{array}$ & $\begin{array}{c}0.0000 \\
0\end{array}$ & 1.1624110 & 1.16390 & $\begin{array}{c}0.001 \\
5\end{array}$ \\
\hline $\begin{array}{c}0.000 \\
0\end{array}$ & $\begin{array}{c}0.0000 \\
0\end{array}$ & $\begin{array}{c}5.8000 \\
1\end{array}$ & 1.1766738 & 1.17140 & $\begin{array}{c}-0.005 \\
2\end{array}$ \\
\hline $\begin{array}{c}0.570 \\
0\end{array}$ & $\begin{array}{c}1.8999 \\
9\end{array}$ & $\begin{array}{c}1.5000 \\
0\end{array}$ & 1.1711825 & 1.17020 & $\begin{array}{c}-0.001 \\
0\end{array}$ \\
\hline $\begin{array}{c}0.570 \\
0\end{array}$ & $\begin{array}{c}0.6000 \\
0\end{array}$ & $\begin{array}{c}6.0000 \\
0\end{array}$ & 1.1766511 & 1.17240 & $\begin{array}{c}-0.004 \\
3\end{array}$ \\
\hline $\begin{array}{c}3.000 \\
0\end{array}$ & $\begin{array}{c}1.8999 \\
9\end{array}$ & $\begin{array}{c}6.0000 \\
0\end{array}$ & 1.1478528 & 1.15050 & $\begin{array}{c}0.002 \\
7\end{array}$ \\
\hline $\begin{array}{c}5.000 \\
0\end{array}$ & $\begin{array}{c}1.7000 \\
5\end{array}$ & $\begin{array}{c}5.9000 \\
1\end{array}$ & 1.1515193 & 1.14890 & $\begin{array}{c}-0.002 \\
6\end{array}$ \\
\hline $\begin{array}{c}0.300 \\
0\end{array}$ & $\begin{array}{c}2.0000 \\
0\end{array}$ & $\begin{array}{c}7.0000 \\
0\end{array}$ & 1.1766739 & 1.16840 & $\begin{array}{c}-0.008 \\
2\end{array}$ \\
\hline $\begin{array}{c}0.310 \\
0\end{array}$ & $\begin{array}{c}0.1000 \\
1\end{array}$ & $\begin{array}{c}3.5000 \\
0\end{array}$ & 1.1764046 & 1.17680 & $\begin{array}{c}0.000 \\
4\end{array}$ \\
\hline $\begin{array}{c}0.315 \\
0\end{array}$ & $\begin{array}{c}1.3999 \\
9\end{array}$ & $\begin{array}{c}2.0000 \\
0\end{array}$ & 1.1762710 & 1.17620 & $\begin{array}{c}-0.000 \\
0\end{array}$ \\
\hline $\begin{array}{c}0.265 \\
0\end{array}$ & $\begin{array}{c}1.3999 \\
9\end{array}$ & $\begin{array}{c}4.5000 \\
0\end{array}$ & 1.1741571 & 1.16650 & $\begin{array}{c}-0.007 \\
7\end{array}$ \\
\hline $\begin{array}{c}0.100 \\
0\end{array}$ & $\begin{array}{c}0.6000 \\
0\end{array}$ & $\begin{array}{c}3.0000 \\
0\end{array}$ & 1.1765254 & 1.18080 & $\begin{array}{c}0.004 \\
2\end{array}$ \\
\hline
\end{tabular}

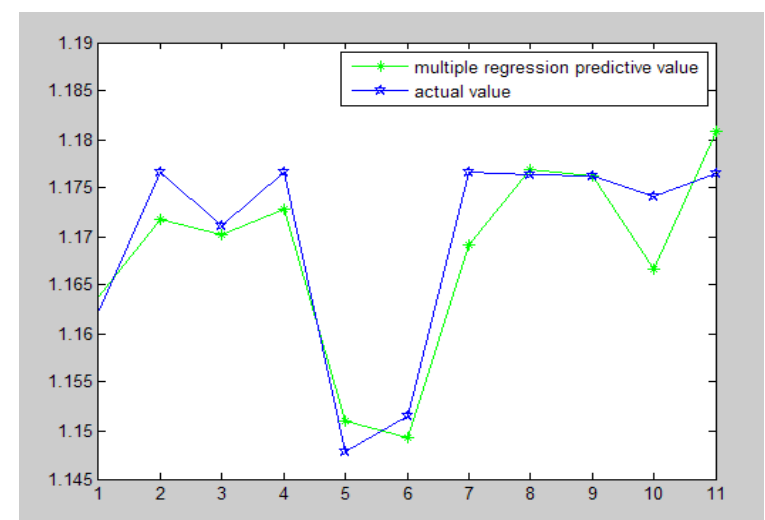

Figure 1-4. Actual and predicted values of diffusion concentration.

The actual value in Figure 1-4 is refers to the calculation results of fluid dynamics model, the green star line represents the multiple regression model prediction, Blue stars line represents the actual value. The figure in the order is the serial number of inspection data, and the ordinate instructed the size of leakage gas diffusion density Combined with figure 1-4 you can see, When diffusion concentration is greater than $1.765 \mathrm{~kg} / \mathrm{m}^{3}$, Model predicted value and actual value have a slightly larger difference; This may be due to leakage gas diffusion time is short, the early trend of diffusion caused by unstable; When the concentration of diffusion in $1.4 \sim 1.764 \mathrm{~kg} / \mathrm{m}^{3}$. The model predicted value and actual value is closer, the forecast effect is better.

\section{CONCLUTION}

In this paper, Firstly through the calculation results in the same experiment conditions compared with calculation results of fluid dynamics model. The multivariate regression model based on univariate regression, can forecast the diffusion of the gas concentration within the error range in a certain degree, Moreover, with the spreading of the gas. The diffusion of the gas is more and more far distance, the diffusion of the gas concentration is more and more small. Wind speed directly affect the spread of leakage gas concentration, And the greater the wind speed, the smaller the diffusion of the gas concentration is. Finally, their simulation results show the effectiveness of the proposed model.

\section{ACKNOWLEDGMENT}

This work is supported by Natural Science Foundation of Inner Mongolia Autonomous Region (No. 2014MS0619), and Inner Mongolia Science and Technology Project (No. 20120304). It's research findings that application system of intelligent decision making technology in agriculture and animal husbandry, by industry innovation talents team of Inner Mongolia Autonomous Region.

\section{REFERENCES}

[1] Jibing Li. Harmful gas transport in the process of simulation and analysis of the leakage diffusion [D]. Cheng Du: Southwest Jiaotong University, 2006, pp.16 (2) 8-10

[2] Xiongjun Yuan, Haipu Bi, Ning Zhou, etc. Dangerous chemicals leakage accident evolution mechanism research [J]. Journal of industrial safety and environmental protection, 2014, 40 (2), pp.21-24.

[3] Dong Yan. Liquid chlorine tank leakage diffusion numerical simulation study [D]. Xi 'an: xi 'an university of science and technology, 2011:13 (2), pp.156-157.

[4] Hou Q. M., Jiao W. L., Zou P. H. The Analysis for the Environmental Impact of Natural Gas Leakage and Diffusion into the Atmosphere [J]. Advanced Materials Research, 2011, pp.225-226.

[5] Zhao P., Zhao Y., Yu Z.. Diffusion Research of Leaked Coal Gas in Steel Plants under Natural Ventilation Conditions[C]. Computational Intelligence and Intelligent Systems - International Symposium, Isica 2010, Wuhan, China, October 22-24, 2010. Proceedings. 2010, pp.173-179.

[6] Right to double the latter, Jie Liu. A nonlinear category identification method of mechanical system [J]. Journal of xi 'an jiao tong university press, 2015, 49 (12), pp.104-111.

[7] Cong Bai, Hongwei Wang, Zhongren Peng. Road transport of dangerous goods in real time monitoring and emergency rescue system development [J]. Science, technology and engineering, 2014, 14 (20) ,pp.298-299.

[8] Guo L., Yuan P., Song Y., et al. Case study and environmental risk assessment of the petrochemical industry[C]. Remote Sensing, Environment and Transportation Engineering (RSETE), 2011 International Conference on. IEEE, 2011,pp.5783-5786.

[9] Valeriy A., Vlasov. Diffusion model of gas hydrate formation from ice [J]. Heat and Mass Transfer, 2016, Vol.52 (3), pp.531-537. 